2019-11-05

\title{
Transport and Redistribution of Radiocesium in Fukushima Fallout through Rivers
}

\section{Taniguchi, $\mathrm{K}$}

http://hdl.handle.net/10026.1/15896

\subsection{1/acs.est.9b02890}

Environmental Science \& Technology

American Chemical Society (ACS)

All content in PEARL is protected by copyright law. Author manuscripts are made available in accordance with publisher policies. Please cite only the published version using the details provided on the item record or document. In the absence of an open licence (e.g. Creative Commons), permissions for further reuse of content should be sought from the publisher or author. 


\section{Transport and Redistribution of Radiocesium in Fukushima Fallout through Rivers}

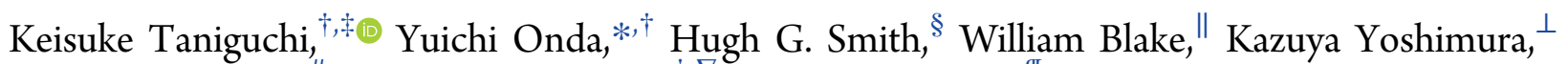
Yosuke Yamashiki, ${ }^{*}$ Takayuki Kuramoto, ${ }^{\ddagger, \nabla}$ and Kimiaki Saito ${ }^{\text {II }}$

${ }^{\dagger}$ Center for Research in Isotopes and Environmental Dynamics, University of Tsukuba, Tsukuba 305-8572, Japan

${ }^{\ddagger}$ Fukushima Prefectural Centre for Environmental Creation, Miharu 963-7700, Japan

${ }^{\S}$ Landcare Research, Private Bag 11052, Palmerston North 4442, New Zealand

"School of Geography, Earth and Environmental Sciences, University of Plymouth, Plymouth PL4 8AA, Devon, U.K.

${ }^{\perp}$ Japan Atomic Energy Agency, Sector of Fukushima Research and Development, 45-169 Sukakeba, Kaihana, Haramachi-ku, Minamisoma 975-0036, Fukushima, Japan

\#Graduate School of Advanced Integrated Studies, Kyoto University, 1 Yoshida-Nakaadachicho, Sakyo, Kyoto 606-8306, Japan

IJapan Atomic Energy Agency, Nuclear Emergency Assistance and Training Center, 178-4-4 Wakashiba, Kashiwa, Chiba 227-0871, Japan

Supporting Information

ABSTRACT: The Fukushima Daiichi Nuclear Power Plant (FDNPP) accident released the most significant quantity of radiocesium into the environment since Chernobyl, and detailed measurements over the initial 5 years provide new insights into fluvial redistribution of radiocesium. We found that the high initial activity concentration of ${ }^{137} \mathrm{Cs}$-bearing suspended sediment in rivers was followed by a steep exponential decline $\left(\lambda_{1}\right)$ which extended to approximately 1 year after the accident, while the rate of initial decline in radiocesium activity concentration in water was an order of magnitude higher than rates measured after Chernobyl. Fluvial transport of ${ }^{137} \mathrm{Cs}$ to the ocean from the Abukuma river totaled 12 $\mathrm{TBq}$ between June 2011 and August 2015 and almost all this radiocesium (96.5\%) was transported in the particulate form. The

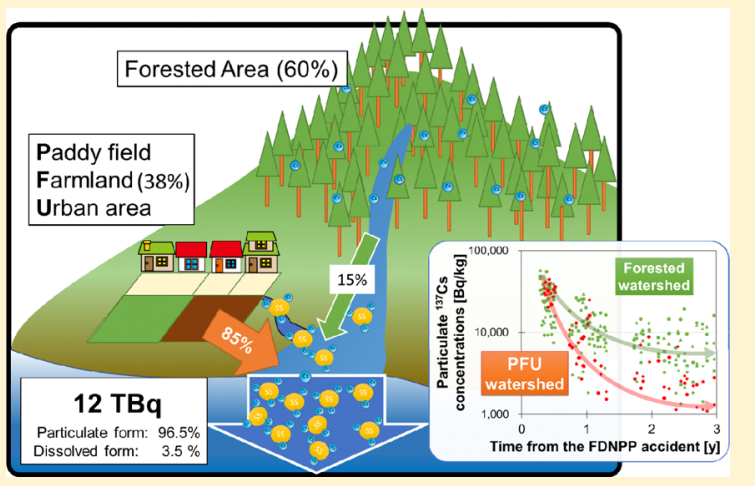
primary sources of ${ }^{137} \mathrm{Cs}$ were paddy fields, farmland, and urban areas [plaque-forming unit (PFU)], discharging $85 \%$ of the exported ${ }^{137} \mathrm{Cs}$ from $38 \%$ of the watershed area. After 1 year, activity concentrations were lower and exhibited a more gradual secondary decline $\left(\lambda_{2}\right)$ which was associated with reduced radiocesium losses from PFU areas, while forest areas continue to represent more stable contaminant stores.

\section{INTRODUCTION}

The Fukushima Daiichi Nuclear Power Plant (FDNPP) accident released the most substantial quantity of radiocesium $\left({ }^{134} \mathrm{Cs}\right.$ and ${ }^{137} \mathrm{Cs}$ with half-lives 2.07 and 30.1 years, respectively) into the environment since Chernobyl, ${ }^{1}$ and the its deposition in the terrestrial environment may present significant radiation dose risk. ${ }^{2,3}$ The recovery of the marine environment from Fukushima contamination is now relatively well understood ${ }^{4}$ including a possible new source from beach sand, ${ }^{5}$ but the pattern of radiocesium redistribution in the terrestrial environment and riverine transport to the ocean is less clear. ${ }^{6}$

Following the 1986 Chernobyl accident, dissolved levels of ${ }^{137} \mathrm{Cs}$ in European rivers and lakes were found to decrease rapidly within several months, ${ }^{7}$ followed by a slow secondary rate of decline. These periods were termed early and intermediate phases. However, few studies measured changes in the levels of particulate ${ }^{137} \mathrm{Cs}$ in rivers. ${ }^{8,9}$ Radiocesium concentrations in rivers vary according to land cover, ${ }^{10}$ and peat-covered areas were observed to produce rapid radiocesium losses. ${ }^{11,12}$ Other studies of radiocesium in rivers are available, but these rely on periodic samplings of typically one month intervals or longer ${ }^{11,13}$ and are, therefore, likely to underestimate radiocesium flux. Rainfall in Fukushima is monsoonal with high-intensity precipitation during typhoon events from August to October. As such, radiocesium redistribution with soil erosion and suspended matter exceeds the dissolved transport, and most transport occurs during only

Received: $\quad$ May 21, 2019

Revised: September 2, 2019

Accepted: September 6, 2019

Published: September 6, 2019 


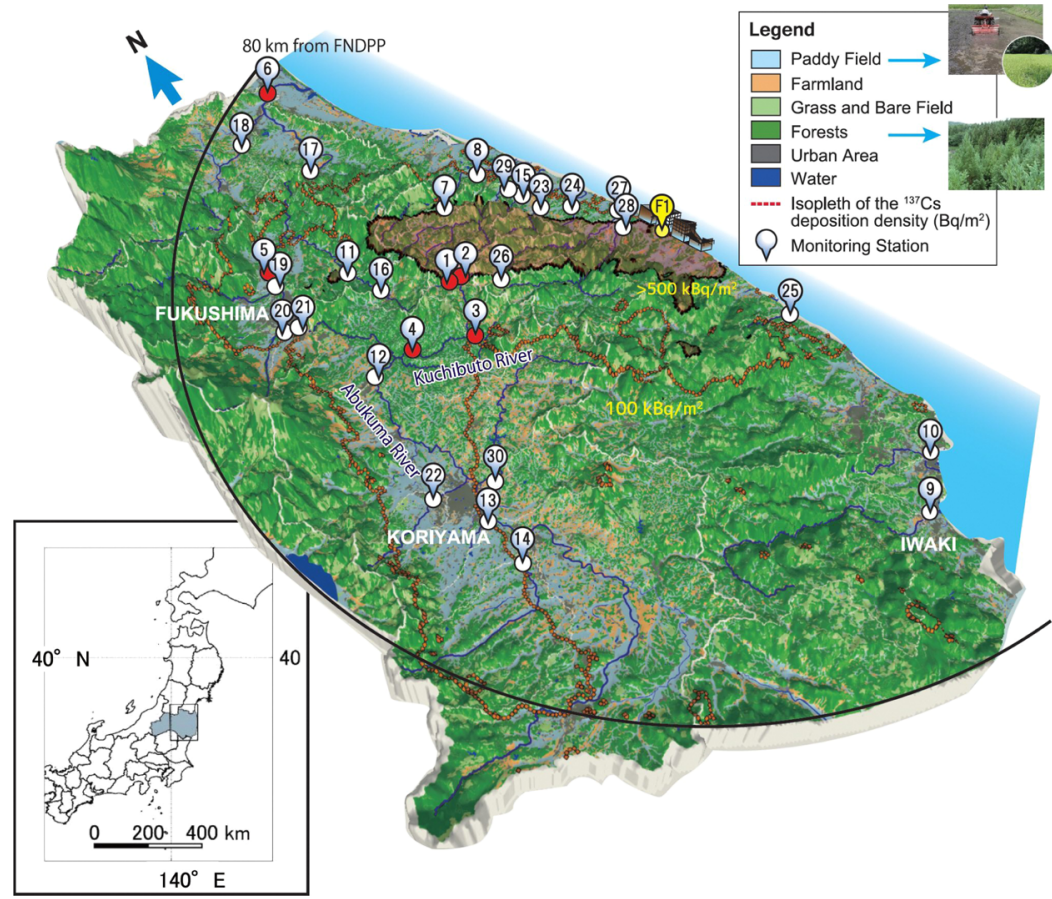

Figure 1. River monitoring stations and land cover within the $80 \mathrm{~km}$ radius zone from the FDNPP. The numbered points indicate the river stations, which commenced at six sites from June 2011 (red) to quantify radiocesium fluxes by measuring discharge and turbidity, and sampling bulk suspended sediment (SS) and water. Periodic SS sampling commenced from August 2011 at 10 sites (nos. 7-16) with discharge and turbidity measurements commencing from December 2012 alongside the installation of a further 14 monitoring sites to give 30 stations in total. This map was compiled by the authors from the maps of the digital elevation, ${ }^{28}{ }^{137} \mathrm{Cs}$ inventory, ${ }^{26}$ and land use types ${ }^{27}$ by using QGIS ver. $2.18 .{ }^{29}$

several days per year, ${ }^{14,15}$ which cannot be quantified by periodic sampling schemes.

Many observational studies have been conducted on rivers in the affected area of the FDNPP accident. Some rely on results based on only a few observations, ${ }^{16-20}$ while others focus on small catchments in forest ${ }^{21-23}$ or paddy field ${ }^{24}$ areas. There has been limited investigation of radiocesium flux for large watersheds during the early phase ${ }^{16}$ and rivers draining the coastal part of Fukushima Prefecture (Hamadori district) during the intermediate phase. ${ }^{25}$ No studies span the initial fast and subsequent intermediate phases. Our study combines investigation of both these phases for watersheds across the fallout zone ranging in size from small headwater streams to large rivers such as the Abukuma that delivers radiocesium directly to the ocean.

Here, we investigate the redistribution of fallout radiocesium and flux in river systems across the terrestrial environment of Fukushima. Our approach combines datasets from the airborne mapping of radiocesium fallout ${ }^{26}$ and land $\operatorname{cover}^{27}$ with an extensive automated network of 30 river monitoring stations (Figures 1 and SI1, and Tables S1, and S2). This unique methodology makes it possible to evaluate the relative contribution of forested versus human-affected areas to riverine radiocesium transport for the first time.

\section{MATERIALS AND METHODS}

Fukushima Region and River-Monitoring Network. The topography, land cover, and ${ }^{137} \mathrm{Cs}$ inventory $\left(\mathrm{Bq} \mathrm{m}^{-2}\right)$ of the Fukushima fallout region are shown in Figure 1. Most of the ${ }^{137} \mathrm{Cs}$ (approximately 58\%) was deposited in areas of higher elevation (300-1200 m). More than half of this area is in the Abukuma River basin (18 sites), where major population centers of Koriyama and Fukushima City are traversed by the
Abukuma River. The 30 continuous monitoring stations (Figure 1) were installed along the Abukuma River as well as on rivers draining coastal catchments (Hamadori district) in Fukushima and Miyagi Prefectures as part of a Japanese

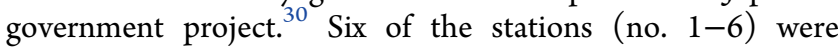
subject to longer-term measurements that began between June and July 2011. ${ }^{15}$ These stations are nested and stretch from the headwater Kuchibuto (KU, sites 2, KM, site 3, and $\mathrm{KD}$, site 4) and Mizusakai (Miz, site 1), an area that was heavily contaminated in its upper reaches, through to the main Abukuma channel (Fus, site 5) and finally the tidal basin outlet channel at Iwanuma (Iwa, site 6). Monitoring at 24 stations from sites 7-30 commenced between October 2012 and January 2013 and covers most of the contaminated area including the Hamadori coastal catchments: Mano (Man, sites 7, and Oji, site 8), Same (Mat, site 9), Fujiwara (Ona, site10), Niida (Kit, site 15 and Har, site 29), Ota (Ota, site 23), Odaka (Oda, site 24), Asami (Asa, site 25), and Ukedo (Tsus, site 26 and Uke, site 27 and Tak, site 28) rivers. These high spatial resolution measurements span a range of catchment characteristics (area, relief, and land cover) and contamination levels to enable an analysis of the effects of land use and management on recovery rates.

Spatial Datasets. Watershed areas $S\left(\mathrm{~km}^{2}\right)$ and averaged initial deposition $D\left(\mathrm{kBq} \mathrm{m}^{-2}\right)$ at each monitoring site were obtained from the $10 \mathrm{~m}$ digital elevation model of the Fundamental Geospatial Data ${ }^{28}$ and the "Reconstructed initial fallout map of the Fukushima accident-derived radiocesium ${ }^{26}$, respectively (Table $\mathrm{S} 1$ ).

Land-use data were derived from the " 3 rd to 5 th vegetation survey by Biodiversity Center of Japan ${ }^{27 ”}$. The original classification of 14 groups was simplified into 7 groups of related functional types, which were paddy field, farmland, 
grass and bare fields, forest, urban area, aquatic, and other. In the $80 \mathrm{~km}$ radius from the FDNPP, the proportions were paddy field $17 \%$, farmland $6.4 \%$, grass and bare fields $13 \%$, forest $60 \%$, urban area $3.1 \%$, aquatic, and others $0.0 \%$ (Table S2). As shown in Table S3, the paddy field, farmland, and urban areas show significant positive correlations with each other. Therefore, we defined the sum of the three land use types as "plaque-forming unit (PFU)", which represents a human-affected area.

Evacuation and Government-Led Decontamination. After the FDNPP accident, the Japanese government ordered evacuation of 11 municipalities and decided to conduct decontamination works based on the additional exposure dose per year. ${ }^{31}$ Municipalities containing areas where the additional exposure dose per year exceeded $1 \mathrm{mSv}$ (Intensive Contamination Survey Area, ICSA) were subject to decontamination work based on the result of the air dose rate survey. In areas where the additional exposure dose per year exceeded $20 \mathrm{mSv}$ (special decontamination area, SDA) located in the 11 municipalities, the Ministry of Environment conducted the decontamination and then lifted the evacuation order. The proportion of decontaminated area was limited compared to the monitored watersheds. Only $4.0 \%$ of the study area (i.e. $413 \mathrm{~km}^{2}$ of agricultural land in Miyagi and Fukushima prefecture) $)^{31,32}$ was decontaminated by Mar. 2018.

The watersheds of site 1 (Miz) and 2 (KU) could be used for the evaluation of the impact of decontamination on the riverine radiocesium transport. The first reason was that human activities except for the decontamination works had been interrupted during the study period due to the evacuation order. The second reason was that we could confirm that almost all the agricultural land (about $36 \%$ of the total area) in the two watersheds were decontaminated ${ }^{31}$ because the sum of the two watersheds corresponded to the SDA in Kawamata town.

River Measurements. The following instruments were installed at each river measurement station: time-integrated SS samplers, ${ }^{33}$ turbidity meters (Analyte turbidity meter 3000NTU, MacVan), and water-level gauges. 24 of the sites were located near water-level monitoring stations maintained by Fukushima Prefecture and Ministry of Land, Infrastructure, Transport and Tourism (MLIT). ${ }^{34,35}$ For the other six sites located in small watersheds (sites 1, 2, 3, 7, 15, 26), we installed water-level gauges (Rugged Troll 100, In Situ Inc.). The time-integrated samplers were located $0.2-5 \mathrm{~m}$ away from the edge of the riverbank and 5-20 $\mathrm{cm}$ above the riverbed, depending on the river conditions (i.e., width, depth, and structure of the riverbed) to keep the sampler submerged at the base flow. The turbidity meters and water-level gauges were set to record measurements every $10 \mathrm{~min}$. River water samples (20 L) were also collected at each site for measurement of dissolved radiocesium between 2011 and 2014.

Bulk sampling of SS typically occurred at 2-4 weekly intervals. The SS samples were dried $\left(105{ }^{\circ} \mathrm{C}, 24 \mathrm{~h}\right)$ and disaggregated using a mortar and pestle. These samples were analyzed for grain size by laser particle size analysis (SALD3100 , Shimadzu) and by gamma spectrometry for ${ }^{134} \mathrm{Cs}$ and ${ }^{137}$ Cs (EGC25-195-R, Canberra-Eurisys). All the data in this paper were corrected to the sampling collection date. Each surface river water sample was passed through a membrane filter $(0.45 \mu \mathrm{m}$ pore size, Millipore). Dissolved radiocesium in the filtrate was concentrated by ammonium molybdophos- phate. ${ }^{18}$ SS concentrations and flow were calculated from turbidity and water-level measurements, respectively. Combining measurements of flow, SS concentrations, and the radionuclide activity concentrations from bulk sediment samples allowed the estimation of radiocesium flux at each site.

Particle Size Correction of SS. Fine particle size fractions are known to increase radiocesium concentrations in soil and sediments, ${ }^{36,37}$ suggesting that the solid/liquid partitioning distribution coefficient $\left(K_{\mathrm{d}}\right)$ is dependent on particle size composition. ${ }^{37}$ To evaluate the $K_{\mathrm{d}}$ and analyze the relationship between particulate radiocesium concentrations and catchment inventory independent of particle size effects, the particulate radiocesium concentration was normalized using a particle-size correction factor $(P f)$ calculated as follows

$$
P f=\left(S_{\mathrm{r}} / S_{\mathrm{s}}\right)^{v}
$$

where $S_{\mathrm{r}}$ and $S_{\mathrm{s}}$ are the specific surface areas of the reference sample and analysis target sample, respectively. Specific surface area was estimated using the grain size distribution of the sample and the spherical approximation of particles in each size class. The exponent coefficient $v$ is constant. Because factors such as chemical and/or mineral compositions can affect $v$, this study applied a value for $v(0.65)$ obtained for sediments in the Abukuma River. ${ }^{38}$ The specific surface area of SS samples collected at site $4(\mathrm{KU})$ on 27 June $2011\left(0.409 \mathrm{~m}^{2} \mathrm{~g}^{-1}\right)$ was applied for the $S_{\mathrm{r}}$ in this study. The particulate radiocesium concentrations of $S_{\mathrm{s}}$ samples obtained at other sites were normalized for the effect of particle size by dividing the concentration by Pf. The detailed procedure was reported by Yoshimura et al. ${ }^{18}$

Time Series Analysis of Particulate ${ }^{137}$ Cs Concentrations. To evaluate regional variation, the particulate ${ }^{137} \mathrm{Cs}$ activity concentrations $C(t)\left(\mathrm{Bq} \mathrm{kg}^{-1}\right)$ was normalized by the average initial ${ }^{137} \mathrm{Cs}$ inventory $\mathrm{D}\left(\mathrm{Bq} \mathrm{m}{ }^{-2}\right)$.

$$
C^{\prime}(t)=C(t) / D
$$

$C^{\prime}(t)\left(\mathrm{m}^{2} \mathrm{~kg}^{-1}\right)$ is the normalized ${ }^{137} \mathrm{Cs}$ concentration. After the Chernobyl accident, the time change in riverine ${ }^{137} \mathrm{Cs}$ concentrations may have multiple phases of the decline in the first 10 years (i.e. early and intermediate phases). ${ }^{39}$ Based on the previous analysis, we separated the monitoring period into first and second periods. The former is between June 2011 and March 2012, the latter is between April 2012 and August 2015. $C^{\prime}(t)$ for each monitoring site was fitted to the following decay functions

$$
\begin{aligned}
& C^{\prime}(t)=a_{1} \mathrm{e}^{-\lambda 1 t} \\
& C^{\prime}(t)=a_{2} \mathrm{e}^{-\lambda 2 t}
\end{aligned}
$$

where $a_{1}$ and $a_{2}$ are scaling factors and $\lambda_{1}$ and $\lambda_{2}$ are declining rates for the first and second periods. The effective ecological half-lives $T_{\text {eff } 11}$ and $T_{\text {eff } 2}$ for the two periods could be calculated by $\ln (2)$ divided by $\lambda_{1}$ and $\lambda_{2}$. The $a_{1}, a_{2}, \lambda_{1}, \lambda_{2}$, $T_{\text {eff } 1}$, and $T_{\text {eff } 2}$ values for each monitoring site are shown in Table S4. The $R^{2}$ values of eqs 3 and 4 were not high. One possible reason relates to the variability in the radioactivity ratio for glossy Cs-rich microparticles in the SS samples (the radioactivity ratio between the microparticles and the total ranged from 1.3 to $67 \%) .{ }^{40}$ Another reason is that the grain size distributions may have varied in response to variations in precipitation. 

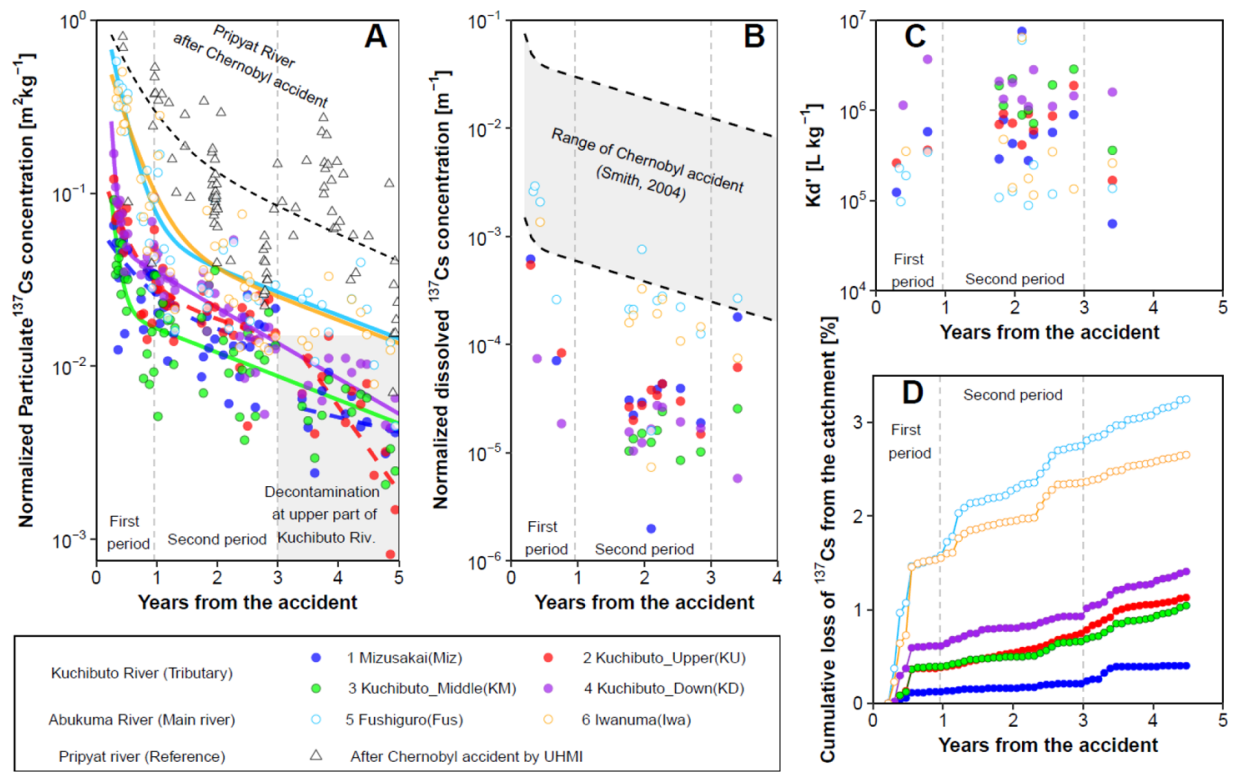

Figure 2. (A) Temporal changes in particulate ${ }^{137} \mathrm{Cs}$ concentration normalized to the initial deposition of the watershed, $C^{\prime}(t)$. No particle size correction was applied to compare the Fukushima and Chernobyl dataset. The lines show the fitted double exponential equation. For site 6 (Iwa), $C^{\prime}(t)$ can be expressed as $C^{\prime}(t)=0.868 \mathrm{e}^{-2.86 t}+0.0636 \mathrm{e}^{-0.309 t}$. Decontamination of the upper Kuchibuto river was conducted after the third year. The triangles show the data in Pripyat river after the Chernobyl accident, ${ }^{43}$ and the dotted line shows the fitted double exponential equation $\left(C^{\prime}(t)\right.$ $=1.02 \mathrm{e}^{-2.15 t}+0.243 \mathrm{e}^{-0.359 t}$.) (B) Normalized dissolved ${ }^{137} \mathrm{Cs}$ concentration. (C) Apparent $K_{\mathrm{d}}$ value. (D) Cumulative loss of particulate ${ }^{137} \mathrm{Cs}$ from the watersheds of sites 1-6. Monthly flux was accumulated from June 2011 and then normalized by the initial deposition density.

Data Processing and Analysis of ${ }^{137}$ Cs Flux. Fluxes of SS and radiocesium for the period up to August 2015 are summarized for both the longer-term monitoring stations in the Abukuma basin and all stations across the fallout region (Table S1). Synchronous data for the six longer-term stations span the period August 2011 to late August 2015, totaling 4 years of measurements (there was a gap in monitoring from May to August 2012). The synchronous period of monitoring across all the stations was from October 2012 to August 2015. Fluxes were determined for monthly intervals. The SS and radiocesium flux data were sometimes unavailable because of the lack of water-level and turbidity data. Gap filling procedures for the monthly flow $Q$ and monthly SS load Ls were then applied. A regression equation between monthly mean precipitation in the basin $P(\mathrm{~mm})$ and $Q\left(\mathrm{~kg} \mathrm{month}^{-1}\right)$ was developed as follows.

$$
Q(P)=c \mathrm{e}^{d p}
$$

where $c(\mathrm{~kg})$ and $d\left(\mathrm{~mm}^{-1}\right)$ are constants computed by fitting for each site (Table S5). $P$ was determined using the Thiessen method. ${ }^{41}$ This method divides the catchment area into polygons that include respective rain gauges. The average rainfall of the entire catchment is then assumed to be a weighted average of the observed rainfall. Each polygon is bordered by perpendicular bisectors drawn between adjacent rain gauges. Based on the rainfall data at 50 rain gauges located near the monitoring area, ${ }^{42}$ mean hourly rainfall in the basin was converted to monthly rainfall data. However, correlations were low at monitoring stations located just downstream of a dam (Man, site 7, Sen, site 19 etc.) and for those with small catchment areas where there were fewer meteorological stations (Asa, site 25 etc.). Gaps in the SS load Ls were filled using the following power function

$$
L s(Q)=a Q^{b}
$$

where $a$ and $b$ are constants derived for each monitoring site based on monthly measurements between October 2012 and October 2014. The ratio of period in which the gap filling procedure was applied to the SS load Ls ranged between 0 and $72 \%$ of the period, with a mean of $29 \%$. Equation 6 exhibited a mean coefficient of determination $\left(R^{2}\right)$ value of 0.73 for 28 sites, with values for individual sites ranging between 0.26 and 0.94 (Table S5). Particulate ${ }^{137}$ Cs fluxes $L\left(B q\right.$ month $^{-1}$ ) were estimated from flow $Q$ as follows

$$
L=C(t) \times L s(Q)
$$

where Ls is the flux of SS $\left(\mathrm{kg} \mathrm{month}{ }^{-1}\right)$ shown in eq 6 .

The gap filling procedures enabled the estimation of the total flow, SS load, and radiocesium flux at monthly intervals for all monitoring stations. This allowed direct comparison of data from all stations spanning the period with synchronous data. It also enabled the most complete estimate to date of the total flux to the ocean from the monitored rivers. All estimated monthly fluxes are shown in Tables S6 and S7.

${ }^{137} \mathrm{Cs}$ Flux and Land Use Analysis. The monthly ${ }^{137} \mathrm{Cs}$ fluxes $L$ and rainfall $P$ for each monitoring site were accumulated to ${ }^{137} \mathrm{Cs}$ fluxes for the first and second periods $\left(L_{1}, L_{2}\right.$ and $\left.P_{1}, P_{2}\right) .{ }^{137} \mathrm{Cs}$ fluxes normalized by averaged rainfall, watershed area $S$, and initial ${ }^{137} \mathrm{Cs}$ deposition $D$ of the watersheds for the first and second period $\left(L_{1} / P_{1} S D\right.$ and $L_{2} /$ $\mathrm{P}_{2} \mathrm{SD}$ ) showed positive correlations with coverage of the PFU and negative correlations with the coverage of forest and grass and bare fields. Based on the data at sites 1-6, we calculated multiple regression equations that estimate $L_{1} / P_{1} S D$ and $L_{2} /$ $\mathrm{P}_{2} \mathrm{SD}$ from the coverages of PFU and Forest. These coverages did not show high correlation with each other, unlike grass and bare fields (Table S8). Initial explanatory variables were coverages of PFU and forest. As a result of variable selection by the variable reduction method, these two variables were retained. The multiple regression equations were as follows 


$$
\begin{aligned}
& L_{1} / P_{1} \mathrm{SD}=3.5 \times 10^{-7} w_{\mathrm{pfu}}+3.1 \times 10^{-8} w_{\text {forest }} \\
& p=0.000185(p<0.01) \\
& L_{2} / P_{2} \mathrm{SD}=7.6 \times 10^{-8} w_{\mathrm{pfu}}+1.2 \times 10^{-8} w_{\text {forest }} \\
& p=0.0026(p<0.01)
\end{aligned}
$$

where $w_{\text {pfu }}$ and $w_{\text {forest }}$ are the coverages of PFU and forested area.

\section{RESULTS AND DISCUSSION}

Declining Radiocesium Activity Concentrations in Rivers. The activity concentration of radiocesium in suspended particles (normalized by initial deposition density) $C^{\prime}(t)\left(\mathrm{m}^{2} \mathrm{~kg}^{-1}\right)$ at six longer-term river stations installed in June $2011^{15}$ shows a steep exponential decline (defined as $\lambda_{1}$ ) (sites $1-6$ in Figure 1). The transition to the more gradual secondary decline $\left(\lambda_{2}\right)$ occurs approximately 1 year after the accident based on regression analysis across all six longer-term river stations (Figure 2a, Table 1 ). The radioactive decay of ${ }^{137} \mathrm{Cs}\left(0.023 \mathrm{y}^{-1}\right)$ is negligible over our study period. The triangle points fitted with dashed line show the trend of particulate ${ }^{137} \mathrm{Cs}$ in the Pripyat River, Chernobyl-affected area, indicating a gradual decline through time. ${ }^{43}$ No analysis is available on the particulate $\lambda_{1}$ value for rivers affected by Chernobyl fallout because there were not enough published data on the suspended ${ }^{137} \mathrm{Cs}$ just after the accident. ${ }^{8}$ Trends in the rate of decline differed between monitoring sites; a marked and greater rate of decrease $\left(\lambda_{1}\right)$ in activity concentration occurred in the Abukuma River, but a lesser decrease occurred upstream in the Kuchibuto River because the human activity in the watersheds had been interrupted due to the evacuation order. $^{31}$

The dissolved radiocesium activity concentration in river water normalized by deposition density $\left(\mathrm{Bq} \mathrm{m}^{-2}\right)$ was typically 1 order of magnitude lower than the Chernobyl affected sites (Figure $2 \mathrm{~b}) .{ }^{13,43}$ The dissolved activity concentration of the radiocesium declined continuously with time, contributing to the rapid recovery of contamination levels in freshwater fish in the Fukushima-affected area. ${ }^{44}$ The apparent distribution coefficient $\left(K_{\mathrm{d}}{ }^{\prime}\right)^{18}$ normalized by particle size did not show any significant change throughout the first 4 years (Figure $2 c$ ). This contrasts with the Chernobyl-affected area where $K_{\mathrm{d}}{ }^{\prime}$ increased during the initial 4 years, ${ }^{13}$ where clay fixation was thought to be important for controlling dissolved ${ }^{137} \mathrm{Cs}$ levels. ${ }^{45}$ All averaged $K_{\mathrm{d}}$ data are shown in Table S10.

Effect of Decontamination Works in the Kuchibuto River. The range in secondary decline $\left(\lambda_{2}\right) 1-5$ years after the fallout for the remaining 24 monitoring stations was similar (0.04-0.66, Table S4) to those reported for particulate radiocesium in the Chernobyl-affected areas. ${ }^{8}$ Two headwater watersheds of the Kuchibuto River (Miz, site 1 and KU site2) had the lowest $\lambda_{2}$ values of 0.26 and 0.35 in the six sites (Table 1) but showed rapid decrease 3 years after the accident in Kuchibuto Upper (KU, site 2). The statistically significant rapid decline at KU (Wilcoxon rank-sum test; Table S9) corresponded with the government-led decontamination activities (Figure S1), including the removal of farmland topsoil ( $5 \mathrm{~cm}$ depth) and washing of impervious surfaces ${ }^{46}$ across $2.2 \%$ of the $80 \mathrm{~km}$ radius zone and $36 \%$ of the catchment of KU. Therefore, in the decontaminated area, the

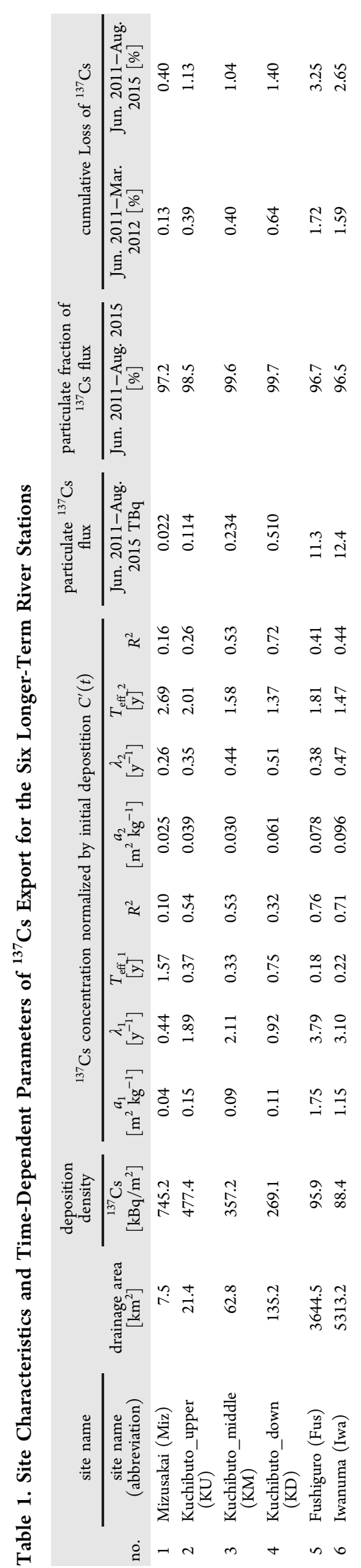



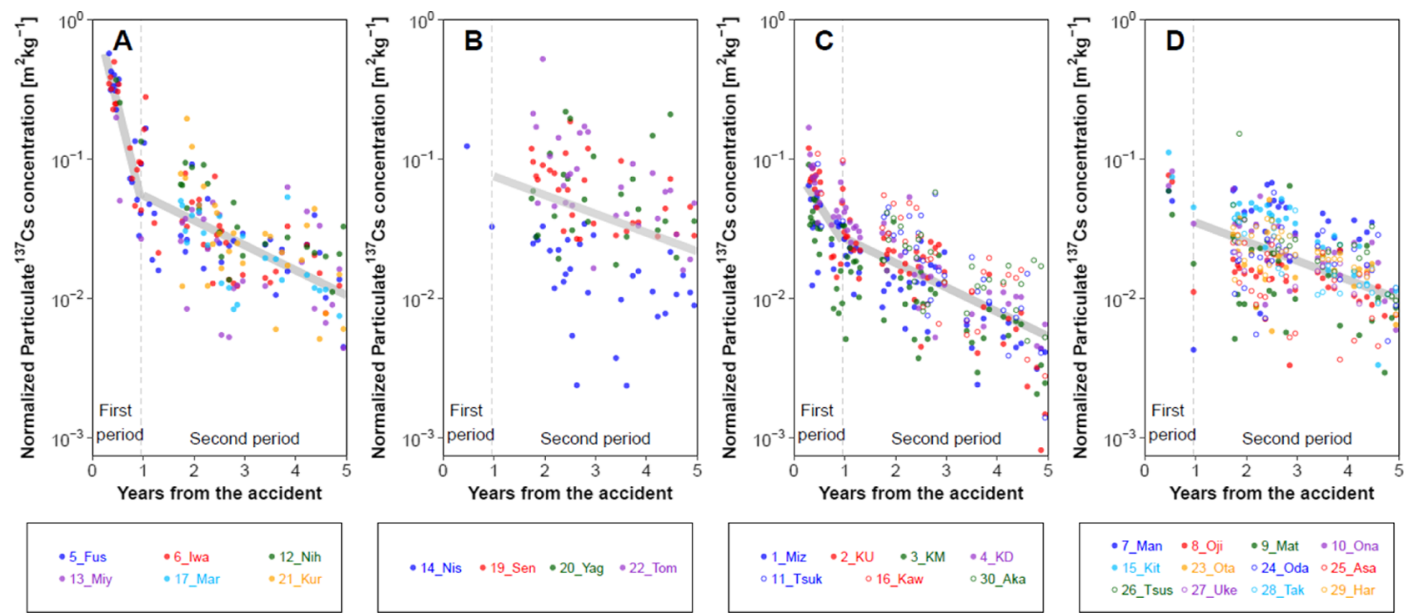

Figure 3. Temporal changes in normalized particulate ${ }^{137} \mathrm{Cs}$ activity concentrations for 30 river measurement sites. (A) Abukuma mainstream (B) Abukuma tributaries (West), (C) Abukuma tributaries (East), and (D) coastal catchments (Hamadori district). Numbered labels for each watershed correspond to labels in Figure 1. Grey solid lines show regression curves for $\lambda_{1}$ and $\lambda_{2}$ periods calculated by the geometric mean values of each area. In the plot (C), sites 1_Miz and 2_KU were excluded from the calculation because of the influence of decontamination activities. Data from site 18 was not available because we did not collect SSs at the site.

First period (June 2011 to February 2012)
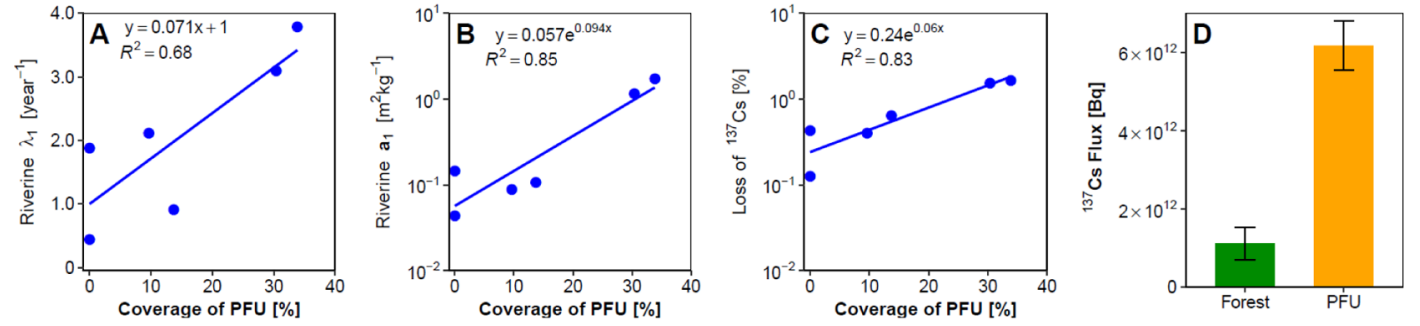

Second period (March $2012-$ )
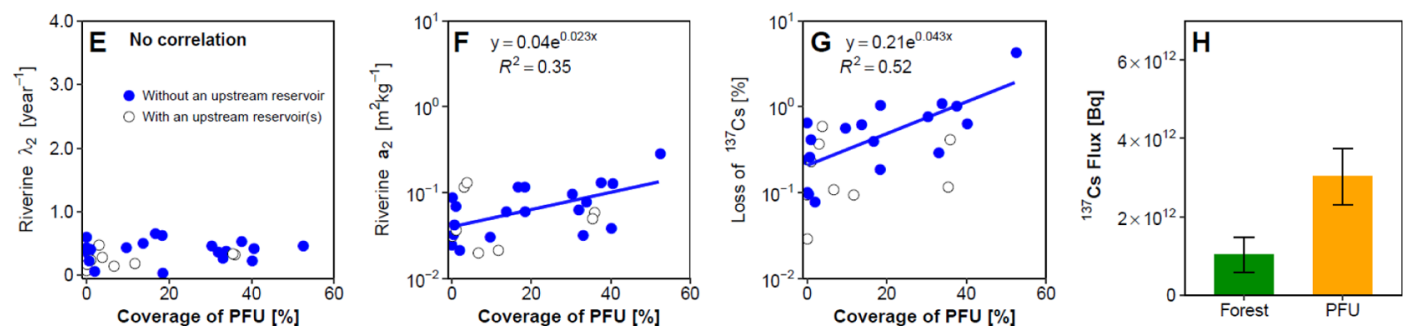

Figure 4. Relationship between the combined coverage of PFU and (A) declining riverine rate $\lambda_{1}$, (B) scaling factor $a_{1}$, (C) loss of particulate ${ }^{137} \mathrm{Cs}$ from the watersheds, and (D) particulate ${ }^{137} \mathrm{Cs}$ flux at the Iwanuma site during the first period. (E) Declining riverine rate $\lambda_{2}$, (F) scaling factor $a_{2}$, and $(\mathrm{G})$ loss of particulate ${ }^{137} \mathrm{Cs}$ from the watersheds in the second period. Open circles indicate sampling sites affected by the presence of upstream reservoirs. $(\mathrm{H})$ Particulate ${ }^{137} \mathrm{Cs}$ flux at the Iwanuma site during the second period.

period after 3 years from the accident may be inferred as the third period.

Radiocesium Flux for the Longer-Term Monitoring Stations. Fluxes of ${ }^{137} \mathrm{Cs}$ with suspended matter equated to 22-510 GBq from 2011 to 2015 for the nested Kuchibuto tributary monitoring stations (Figure 1, sites 1-4), which amounted to a cumulative loss of $0.4-1.4 \%$ relative to watershed ${ }^{137} \mathrm{Cs}$ inventories. The lowest watershed losses (Miz, $\mathrm{KU}$ ) occurred in the evacuation area, where residence and cultivation have been prohibited. For example, only $0.4 \%$ loss of ${ }^{137} \mathrm{Cs}$ occurred in the first 5 years in Miz, whereas after April 2014, sediment flux increased threefold compared to discharge, suggesting a decontamination effect related to topsoil disturbance, although this trend is not evident at the downstream Abukuma sites (site 5, Fus and site 6, Iwa)
(Table S11). However, because of the prior decline in particulate ${ }^{137} \mathrm{Cs}$ activity concentrations caused by decontamination works, the ${ }^{137} \mathrm{Cs}$ flux at Miz exhibited negligible change despite the increased sediment flux (Table S6).

The particulate fraction of ${ }^{137} \mathrm{Cs}$ was calculated as $96.5-$ 99.7\% by the $K_{d}{ }^{\prime}, Q$ and Ls values ${ }^{39}$ (Table 1 ), which greatly exceeds the Chernobyl-affected areas $(20-76 \%) .{ }^{47}$ This difference is attributed to elevated losses of suspended matter from agricultural and urban areas triggered by intense seasonal rainfall. In the lower reach of the Abukuma River (Fus site 5), $3.25 \%$ of the watershed inventory has been transported by the river in particulate and dissolved forms, which is at least an order of magnitude higher than rates measured after Chernobyl, $^{48}$ except for those areas covered by fibrous peat. $^{11,12}$ 
Factors Controlling the Decline in Radiocesium with SS. The declining trends in particulate ${ }^{137} \mathrm{Cs}$ activity concentrations generally exhibit an order of magnitude in scatter between watersheds. We found different declining trends between geographic areas; more rapid decline in Abukuma mainstream (A) and Abukuma East tributaries (C) but slower decline in Abukuma West tributaries (B) and coastal catchments (D) (Figure 3).

We investigate the factors controlling different declining trends between watersheds across the fallout zone. The relationship between $\lambda_{1}\left(\mathrm{y}^{-1}\right)$ and land cover type (\%) showed marked positive correlations with PFU coverage (Figure 4A), but no clear relationship during the second period (Figure 4E). The scaling factor, $a_{1}$, and PFU also show high correlation during the first period (Figure 4B) but not during the second period (Figure 4F), indicating higher initial activity concentrations flowing from PFU areas. Larger PFU coverage also corresponds to increasing loss of ${ }^{137} \mathrm{Cs}$ from watersheds during both the first and second periods (Figure 4C), but the relation is less evident during the second period (Figure 4G). These data suggest the rapid initial flushing of high concentration ${ }^{137} \mathrm{Cs}$ from PFU areas as reported in previous studies on the runoff from paddy fields ${ }^{49}$ and urban wastewater. ${ }^{50,51}$

Riverine radiocesium flux was used in the multiregression analysis to estimate contributions according to land use sources (eqs 8 and 9). This implied that 6.1 TBq of the ${ }^{137} \mathrm{Cs}$ flowing from PFU areas and $1.1 \mathrm{TBq}$ from forested area during the 10 months of the first period (Figure 4D), but the flux and the relative difference in contributions from the contaminant sources became smaller during the second period; 3.0 TBq from PFU area and 1.0 TBq from forested area over 3 years (Figure $4 \mathrm{H}$ ). This analysis suggests that forest areas contributed less to particulate ${ }^{137} \mathrm{Cs}$ flux and represent more stable contaminant stores. ${ }^{22}$ This contrast in radiocesium flux between PFU and forested areas is supported by studies measuring runoff from paddy field, farmland, and small catchments in forested areas. ${ }^{24,49,52,53}{ }^{137} \mathrm{Cs}$ flux from paddy fields rapidly decreased, while the flux from forested area decreased more slowly.

The highest ${ }^{137} \mathrm{Cs}$ activity concentrations occur at the soil surface, ${ }^{54}$ and the rapid initial losses of particulate-bound ${ }^{137} \mathrm{Cs}$ with intense rainfall are concentrated in paddy field and urban areas. In paddy fields, the initial preferential discharge of highly contaminated fine particulate matter is driven by agricultural activity, that is puddling, ${ }^{24}$ followed by physical mixing with deeper uncontaminated soil leading to rapid downward migration $^{55,56}$ and dilution, resulting in the faster rate of decline in riverine particulate ${ }^{137} \mathrm{Cs}$ activity concentrations. ${ }^{49}$ When comparing our results with those for Chernobyl, one of the main differences is the absence of significant ongoing human disturbance in the Chernobyl-affected area after the accident, where forest and abandoned agricultural land are the primary land cover. ${ }^{20,43}$

Our results show how rapid recovery from Fukushima fallout is highly localized and dependent on land use. The primary sources of ${ }^{137} \mathrm{Cs}$ were estimated to be human-affected areas (i.e. PFU), discharging $85 \%$ of ${ }^{137} \mathrm{Cs}$ from $38 \%$ of the watershed area. The intense monsoon rainfall enhances the effect of remediation in paddy fields and urban areas. ${ }^{57}$ Land use is a key factor controlling the sources of suspended particulate matter entering river networks, contributing to declining rates of radiocesium flux. Against the background of rapid expansion of nuclear power in Asia and elsewhere in the world, our findings have a critical bearing on future contingency and remediation planning to address fallout contamination of populated areas.

\section{ASSOCIATED CONTENT}

\section{S Supporting Information}

The Supporting Information is available free of charge on the ACS Publications website at DOI: 10.1021/acs.est.9b02890.

Datasets from the airborne mapping of radiocesium fallout and land cover with an extensive automated network of 30 river monitoring stations (PDF)

\section{AUTHOR INFORMATION}

\section{Corresponding Author}

*E-mail: onda@geoenv.tsukuba.ac.jp.

ORCID $\odot$

Keisuke Taniguchi: 0000-0002-3328-7808

Present Address

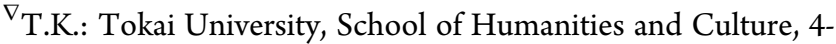
1-1 Kitakaname, Hiratsuka, Kanagawa 259-1292, Japan

\section{Notes}

The authors declare no competing financial interest.

\section{ACKNOWLEDGMENTS}

This work was partially supported by the Ministry of Education, Culture, Sports and Science (MEXT), and Nuclear Regulation Authority (NRA), Japan, Grant-in-Aid for Scientific Research on Innovative Areas grant number 24110005.

\section{REFERENCES}

(1) Katata, G.; Chino, M.; Kobayashi, T.; Terada, H.; Ota, M.; Nagai, H.; Kajino, M.; Draxler, R.; Hort, M. C.; Malo, A.; Torii, T.; Sanada, Y. Detailed Source Term Estimation of the Atmospheric Release for the Fukushima Daiichi Nuclear Power Station Accident by Coupling Simulations of an Atmospheric Dispersion Model with an Improved Deposition Scheme and Oceanic Dispersion Model. Atmos. Chem. Phys. 2015, 15, 1029-1070.

(2) Saito, K.; Tanihata, I.; Fujiwara, M.; Saito, T.; Shimoura, S.; Otsuka, T.; Onda, Y.; Hoshi, M.; Ikeuchi, Y.; Takahashi, F.; Kinouchi, N.; Saegusa, J.; Seki, A.; Takemiya, H.; Shibata, T. Detailed Deposition Density Maps Constructed by Large-Scale Soil Sampling for Gamma-Ray Emitting Radioactive Nuclides from the Fukushima Dai-Ichi Nuclear Power Plant Accident. J. Environ. Radioact. 2015, 139, 308-319.

(3) Andoh, M.; Nakahara, Y.; Tsuda, S.; Yoshida, T.; Matsuda, N.; Takahashi, F.; Mikami, S.; Kinouchi, N.; Sato, T.; Tanigaki, M.; Takamiya, K.; Sato, N.; Okumura, R.; Uchihori, Y.; Saito, K. Measurement of Air Dose Rates over a Wide Area around the Fukushima Dai-Ichi Nuclear Power Plant through a Series of CarBorne Surveys. J. Environ. Radioact. 2015, 139, 266-280.

(4) Buesseler, K.; Dai, M.; Aoyama, M.; Benitez-Nelson, C.; Charmasson, S.; Higley, K.; Maderich, V.; Masqué, P.; Morris, P. J.; Oughton, D.; Smith, J. N. Fukushima Daiichi-Derived Radionuclides in the Ocean: Transport, Fate, and Impacts. Annu. Rev. Mar. Sci. 2017, 9, 173-203.

(5) Sanial, V.; Buesseler, K. O.; Charette, M. A.; Nagao, S. Unexpected Source of Fukushima-Derived Radiocesium to the Coastal Ocean of Japan. Proc. Natl. Acad. Sci. U.S.A 2017, 114, 11092-11096.

(6) Evrard, O.; Laceby, J. P.; Lepage, H.; Onda, Y.; Cerdan, O.; Ayrault, S. Radiocesium Transfer from Hillslopes to the Pacific Ocean after the Fukushima Nuclear Power Plant Accident: A Review. J. Environ. Radioact. 2015, 148, 92-110. 
(7) Santschi, P. H.; Bollhalder, S.; Farrenkothen, K.; Lueck, A.; Zingg, S.; Sturm, M. Chernobyl Radionuclides in the Environment: Tracers for the Tight Coupling of Atmospheric, Terrestrial, and Aquatic Geochemical Processes. Environ. Sci. Technol. 1988, 22, 510516.

(8) Monte, L. A collective model for predicting the long-term behaviour of radionuclides in rivers. Sci. Total Environ. 1997, 201, $17-29$.

(9) Walling, D. E.; Rowan, J. S.; Bradley, S. B. Sediment-Associated Transport and Redistribution of Chernobyl Fallout Radionuclides. IAHS Publ. 1989, 184, 37-45.

(10) Smith, J. T.; Wright, S. M.; Cross, M. a.; Monte, L.; Kudelsky, A. V.; Saxén, R.; Vakulovsky, S. M.; Timms, D. N. Global Analysis of the Riverine Transport of $90 S$ r and137Cs. Environ. Sci. Technol. 2004, $38,850-857$.

(11) Hilton, J.; Livens, F. R.; Spezzano, P.; Leonard, D. R. P. Retention of Radioactive Caesium by Different Soils in the Catchment of a Small Lake. Sci. Total Environ. 1993, 129, 253-266.

(12) Smith, J. T.; Howard, D. C.; Wright, S. M.; Naylor, C.; Brookes, A. M.; Hilton, J.; Howard, B. J. Use of a Satellite-Derived Land Cover Map to Estimate Transport of Radiocaesium to Surface Waters. Sci. Total Environ. 1998, 209, 1-15.

(13) Sansone, U.; Belli, M.; Voitsekovitch, O. V.; Kanivets, V. V.; Bellia, M.; Voitsekovitchb, O. V.; Kanivetsb, V. 137Cs and 90Sr in water and suspended particulate matter of the Dnieper RiverReservoirs System (Ukraine). Sci. Total Environ. 1996, 186, 257-271.

(14) Matsunaga, T.; Amano, H.; Yanase, N. Discharge of Dissolved and Particulate137Cs in the Kuji River, Japan. Appl. Geochem. 1991, 6, $159-167$.

(15) Yamashiki, Y.; Onda, Y.; Smith, H. G.; Blake, W. H.; Wakahara, T.; Igarashi, Y.; Matsuura, Y.; Yoshimura, K. Initial Flux of SedimentAssociated Radiocesium to the Ocean from the Largest River Impacted by Fukushima Daiichi Nuclear Power Plant. Sci. Rep. 2014, 4, 3714.

(16) Ueda, S.; Hasegawa, H.; Kakiuchi, H.; Akata, N.; Ohtsuka, Y.; Hisamatsu, S. i. Fluvial Discharges of Radiocaesium from Watersheds Contaminated by the Fukushima Dai-Ichi Nuclear Power Plant Accident, Japan. J. Environ. Radioact. 2013, 118, 96-104.

(17) Nagao, S.; Kanamori, M.; Ochiai, S.; Tomihara, S.; Fukushi, K.; Yamamoto, M. Export of 134Cs And137 Cs in the Fukushima River Systems at Heavy Rains by Typhoon Roke in September 2011. Biogeosciences 2013, 10, 6215-6223.

(18) Yoshimura, K.; Onda, Y.; Sakaguchi, A.; Yamamoto, M.; Matsuura, Y. An Extensive Study of the Concentrations of Particulate/Dissolved Radiocaesium Derived from the Fukushima Dai-Ichi Nuclear Power Plant Accident in Various River Systems and Their Relationship with Catchment Inventory. J. Environ. Radioact. 2015, 139, 362-369.

(19) Eyrolle-Boyer, F.; Boyer, P.; Garcia-Sanchez, L.; Métivier, J.-M.; Onda, Y.; De Vismes, A.; Cagnat, X.; Boulet, B.; Cossonnet, C. Behaviour of Radiocaesium in Coastal Rivers of the Fukushima Prefecture (Japan) during Conditions of Low Flow and Low Turbidity-Insight on the Possible Role of Small Particles and Detrital Organic Compounds. J. Environ. Radioact. 2016, 151, 328340.

(20) Konoplev, A.; Golosov, V.; Laptev, G.; Nanba, K.; Onda, Y.; Takase, T.; Wakiyama, Y.; Yoshimura, K. Behavior of accidentally released radiocesium in soil-water environment: Looking at Fukushima from a Chernobyl perspective. J. Environ. Radioact. 2016, 151, 568-578.

(21) Tsuji, H.; Yasutaka, T.; Kawabe, Y.; Onishi, T.; Komai, T. Distribution of Dissolved and Particulate Radiocesium Concentrations along Rivers and the Relations between Radiocesium Concentration and Deposition after the Nuclear Power Plant Accident in Fukushima. Water Res. 2014, 60, 15-27.

(22) Iwagami, S.; Onda, Y.; Tsujimura, M.; Abe, Y. Contribution of Radioactive 137Cs Discharge by Suspended Sediment, Coarse Organic Matter, and Dissolved Fraction from a Headwater Catchment in Fukushima after the Fukushima Dai-Ichi Nuclear Power Plant Accident. J. Environ. Radioact. 2017, 166, 466-474.

(23) Iwagami, S.; Onda, Y.; Tsujimura, M.; Satou, Y.; Konuma, R.; Nishino, M.; Abe, Y. Declining Trend of 137Cs Concentrations and Land Use Effect in Headwater Catchments after the Fukushima DaiIchi Nuclear Power Plant Accident. J. Environ. Radioact. 2017.

(24) Wakahara, T.; Onda, Y.; Kato, H.; Sakaguchi, A.; Yoshimura, K. Radiocesium Discharge from Paddy Fields with Different Initial Scrapings for Decontamination after the Fukushima Dai-Ichi Nuclear Power Plant Accident. Environ. Sci.: Processes Impacts 2014, 16, 25802591.

(25) Nakanishi, T.; Sakuma, K. Trend of 137 Cs Concentration in River Water in the Medium Term and Future Following the Fukushima Nuclear Accident. Chemosphere 2019, 215, 272.

(26) Kato, H.; Onda, Y.; Gao, X.; Sanada, Y.; Saito, K. Reconstruction of a Fukushima Accident-Derived Radiocesium Fallout Map for Environmental Transfer Studies. J. Environ. Radioact. 2019, 105996.

(27) Ministry of the Emvironment. Vegetation survey Lists by prefecture/branch. http://www.biodic.go.jp/trialSystem/EN/vg/vg. html (accessed March 28, 2017).

(28) Geospatial Information Authority of Japan. Fundamental Geospatial Data. http://www.gsi.go.jp/kiban/index.html (accessed April 22, 2017).

(29) QGIS development team. QGIS A Free and Open Source Geographic Information System. http://download.osgeo.org/qgis/ win64/ (accessed July 13, 2019).

(30) Saito, K.; Onda, Y. Outline of the National Mapping Projects Implemented after the Fukushima Accident. J. Environ. Radioact. 2015, 139, 240-249.

(31) Ministry of the Environment. Environmental Remediation. http://josen.env.go.jp/en/ (accessed July 14, 2019).

(32) Ministry of the Environment. Status of decontamination(Intensive Contamination Survey Area). http://josen.env.go.jp/zone/ (accessed July 15, 2019).

(33) Phillips, J. M.; Russell, M. A.; Walling, D. E. Time-Integrated Sampling of Fluvial Suspended Sediment: A Simple Methodology for Small Catchments. Hydrol. Process. 2000, 14, 2589-2602.

(34) Fukushima Prefecture. Fukushima River Basin Integrated Information System. http://kaseninf.pref.fukushima.jp/gis/ (accessed July 13,2019 ).

(35) Ministry of Land Infrastructure Transport and Tourism. Water Information System. http://www1.river.go.jp/ (accessed Jul 13, 2019).

(36) Livens, F. R.; Baxter, M. S. Chemical Associations of Artificial Radionuclides in Cumbrian Soils. J. Environ. Radioact. 1988, 7, 7586

(37) He, Q.; Walling, D. E. Interpreting Particle Size Effects in the Adsorption of $137 \mathrm{Cs}$ and Unsupported $210 \mathrm{~Pb}$ by Mineral Soils and Sediments. J. Environ. Radioact. 1996, 30, 117-137.

(38) Ministry of the Environment. Sampling and analytical method of radionuclide in the aquatic environment. https://www.env.go.jp/ jishin/monitoring/report_method-w_1303.pdf.

(39) Smith, J. T.; Voitsekhovitch, O. V.; Konoplev, A. V.; Kudelsky, A. V. Radioactivity in Aquatic Systems. In Chelnobyl-Catastrophe and Consequences; Smith, J. T., Beresford, N. A., Eds.; Praxis Pablishing, 2005; pp 139-190.

(40) Miura, H.; Kurihara, Y.; Sakaguchi, A.; Tanaka, K.; Yamaguchi, N.; Higaki, S.; Takahashi, Y. Discovery of Radiocesium-Bearing Microparticles in River Water and Their Influence on the Solid-Water Distribution Coefficient (Kd) of Radiocesium in the Kuchibuto River in Fukushima. Geochem. J. 2018, 52, 145-154.

(41) Thiessen, A. H. Precipitation averages for large areas. Mon. Weather Rev. 1911, 39, 1082-1084.

(42) Japan Meteological Agency. Weather Observation Data Search. https://www.data.jma.go.jp/gmd/risk/obsdl/index.php (accessed July 14, 2019) 
(43) Konoplev, A. V.; Deville-Cavelin, G.; Voitsekhovich, O. V.; Zhukova, O. M. Transfer of Chernobyl 137Cs and 90Sr by Surface Run-Off. Radioprotection 2002, 37, 315-318.

(44) Wada, T.; Tomiya, A.; Enomoto, M.; Sato, T.; Morishita, D.; Izumi, S.; Niizeki, K.; Suzuki, S.; Morita, T.; Kawata, G. Radiological Impact of the Nuclear Power Plant Accident on Freshwater Fish in Fukushima: An Overview of Monitoring Results. J. Environ. Radioact. 2016, 151, 144-155.

(45) Smith, J. T.; Fesenko, S. V.; Howard, B. J.; Horrill, A. D.; Sanzharova, N. I.; Alexakhin, R. M.; Elder, D. G.; Naylor, C. Temporal Change in Fallout 137Cs in Terrestrial and Aquatic Systems: A Whole Ecosystem Approach. Environ. Sci. Technol. 1999, 33, 49-54.

(46) Ministry of the Environment. Environmental Remediation in Japan. http://josen.env.go.jp/en/pdf/progressseet_progress_on cleanup_efforts.pdf (accessed May 21, 2019).

(47) Monte, L. Evaluation of Radionuclide Transfer Functions from Drainage Basins of Fresh Water Systems. J. Environ. Radioact. 1995, 26, 71-82.

(48) IAEA. Radiological Conditions in the Dnieper River Basin; IAEA: Vienna, 2006. (IAEA PUB 1230).

(49) Yoshimura, K.; Onda, Y.; Wakahara, T. Time Dependence of the ${ }^{137} \mathrm{Cs}$ Concentration in Particles Discharged from Rice Paddies to Freshwater Bodies after the Fukushima Daiichi NPP Accident. Environ. Sci. Technol. 2016, 50, 4186-4193.

(50) Tsushima, I.; Ogoshi, M.; Yamashita, H.; Harada, I. Behavior of Radioactive Cesium in Wastewater Treatment Plants and Dissolution Test of Contaminated Sewage Sludge. J. Jpn. Soc. Water Environ. 2013, $36,23-28$.

(51) Kamei-Ishikawa, N.; Yoshida, D.; Ito, A.; Umita, T. Cesium and Strontium Loads into a Combined Sewer System from Rainwater Runoff. J. Environ. Manage. 2016, 183, 1041-1049.

(52) Wakiyama, Y.; Onda, Y.; Yoshimura, K.; Igarashi, Y.; Kato, H. Land Use Types Control Solid Wash-off Rate and Entrainment Coefficient of Fukushima-Derived ${ }^{137} \mathrm{Cs}$, and Their Time Dependence. J. Environ. Radioact. 2019, 105990.

(53) Iwagami, S.; Onda, Y.; Sakashita, W.; Tsujimura, M.; Satou, Y.; Konuma, R.; Nishino, M.; Abe, Y. Six-Year Monitoring Study of ${ }^{137} \mathrm{Cs}$ Discharge from Headwater Catchments after the Fukushima Dai-Ichi Nuclear Power Plant Accident. J. Environ. Radioact. 2019, 106001.

(54) Kato, H.; Onda, Y.; Teramage, M. Depth Distribution of ${ }^{137} \mathrm{Cs}$, ${ }^{134} \mathrm{Cs}$, and ${ }^{131} \mathrm{I}$ in Soil Profile after Fukushima Dai-Ichi Nuclear Power Plant Accident. J. Environ. Radioact. 2012, 111, 59-64.

(55) Takahashi, J.; Tamura, K.; Suda, T.; Matsumura, R.; Onda, Y. Vertical Distribution and Temporal Changes of ${ }^{137} \mathrm{Cs}$ in Soil Profiles under Various Land Uses after the Fukushima Dai-Ichi Nuclear Power Plant Accident. J. Environ. Radioact. 2015, 139, 351-361.

(56) Matsuda, N.; Mikami, S.; Shimoura, S.; Takahashi, J.; Nakano, M.; Shimada, K.; Uno, K.; Hagiwara, S.; Saito, K. Depth Profiles of Radioactive Cesium in Soil Using a Scraper Plate over a Wide Area Surrounding the Fukushima Dai-Ichi Nuclear Power Plant, Japan. J. Environ. Radioact. 2015, 139, 427-434.

(57) Yamashita, R.; Murakami, M.; Iwasaki, Y.; Shibayama, N.; Sueki, K.; Saha, M.; Mouri, G.; Lamxay, S.; O, H.; Koibuchi, Y.; Takada, H. Temporal Variation and Source Analysis of Radiocesium in an Urban River after the 2011 Nuclear Accident in Fukushima, Japan. J. Water Environ. Technol. 2015, 13, 179-194. 